book review

\title{
Common Pursuits
}

\section{Ben ClaRke}

UNIVERSITY OF NORTH CAROLINA,

GREENSBORO

\author{
Ben Highmore \\ Ordinary Lives: Studies in the Everyday \\ Routledge, Oxford, 2011 \\ ISBN 9780415461870 \\ RRP \$31.95
}

Cultural studies is founded upon a commitment to the ordinary, to explore, and perhaps most importantly to take seriously, what has been dismissed as trivial or mundane. As pioneering critics such as Raymond Williams and Richard Hoggart recognised, there was already a well-established tradition of cultural analysis in place when they began writing in the nineteen-fifties. The radicalism of the new field did not lie in its concern with culture, which writers such as Matthew Arnold, T.S. Eliot and the Leavises had already recognised as a legitimate subject of study, but in its insistence, as Williams famously observed, that it was 'ordinary', ${ }^{1}$ something possessed and produced by all classes, not just an elite, something embedded in everyday life rather than defined by its separation from it. This argument, which draws on both artistic and anthropological definitions of culture, emerged from a particular history of class division and had clear political implications. As Grant Farred argues, '[m]ore than anything, Cultural Studies was a project intent upon making working class culture an object of serious study, ${ }^{2}$ an attempt to recognise 
the complexity and value of the kinds of communities in which Williams and Hoggart were raised. To argue for the importance of ordinary lives was always also to argue for the importance of the supposedly ordinary people who lived them. Texts such as Hoggart's The Uses of Literacy (1957) explored the density and diversity of workingclass neighbourhoods and the ways in which their structuring ideas were negotiated through particular practices and objects. This formed part of a broader argument that all 'expressive phenomena', as Hoggart described them, including 'styles of dress, linguistic habits, all kinds of manners', ${ }^{3}$ provided opportunities for selffashioning. Ordinary lives were not passive, but characterised by the attempt to create meaning, albeit often from a position of relative cultural and economic powerlessness. The everyday was a site of reinvention and resistance; it could be rich and fulfilling as well as monotonous, liberating as well as oppressive. As such, it was a necessary object of both academic scholarship and political action, categories that insistently bled into one another.

There are, though, particular challenges to interpreting ordinary life. In the first place, as it is the element we inhabit, the baseline against which we define what we sometimes think of as our 'real', significant existence, it is almost by definition taken for granted. Making sense of the ordinary requires an extraordinary labour, capable of dislocating objects and practices from the narratives in which they are normally submerged while simultaneously recognising them as social. Ben Highmore's nuanced and engaging book, Ordinary Lives, is a valuable contribution to such work, combining a wide-ranging analysis of theories of the everyday with close, often personal readings of specific acts and artefacts, from a favourite chair to the 'practice of eating ultra-hot (spicy hot) curries in Britain'. (19) It attempts to practice what Michel de Certeau terms a 'science of singularity', which, Highmore argues, 'means that the particular is studied as if it could contribute to a more general account of the world'. (2) This gloss indicates the text's refusal of generalisations, of any simple idea of representative or typical examples. Highmore's analyses gesture beyond themselves towards an 'account of things' but his conclusions are explicitly 'provisional and contestable'. (2) Ordinary Lives demonstrates possible approaches to the everyday, but does not offer a comprehensive theory that can simply be applied to other objects in other cultural and historical contexts. This openness may frustrate those seeking a complete, off- 
the-peg analytical method, but insists upon the irreducible plurality of the everyday itself, the unique contours and textures of particular objects. Highmore's approach to the ordinary depends on a willingness to 'theorize and present descriptions of everyday life' in ways that 'some might feel are far too literary', (xiii) and his book raises useful questions about the kinds of interpretative and representational techniques necessary to move effectively between the general and particular 'without resorting to platitudes'. (2) Though its necessary, more conventionally academic engagement with theoretical debates is productive, Ordinary Lives is most valuable when Highmore himself is most conspicuously present, when his scholarly and personal voices intersect.

Ordinary Lives is founded upon an argument for a broader aesthetic theory that does not focus exclusively on the response to high art, but 'can maintain an attention towards the wonderfully disparate (but also troublesome and deflating) textures, rhythms and affects of the ordinary'. (21) Highmore insists that this idea of the aesthetic is not a personal innovation, but is grounded in an older understanding of the word as pointing 'with imprecision and unease, to a messy world of sensate perception, a world irreducible to rational meanings or ideation'. ( $\mathrm{x}$ ) In his second chapter he offers a 'very selective account of aesthetic theory', (21) tracing its development from Enlightenment thinkers such as Hume, through the work of John Dewey, to the writings of Jacques Rancière. His reading of such figures enables him to develop his argument that the analysis of passion and emotion must consider the exchanges between individuals and the material world they inhabit, between feelings and objects. Aesthetics "names the exteriority of "interior" life and the sociality of passions as they circulate in ways that are interpersonal and transpersonal', analysing a 'material world made up of seemingly immaterial forces'. (23) What appears, and more significantly feels, most personal is always also social, just as what seems most internal, a matter of private thoughts and feelings, is inseparable from a landscape of concrete objects that shape those who encounter them.

Highmore's 'aesthetics of the ordinary' does not preclude the exploration of art, but this 'is no longer a privileged site' (53) of investigation, and Ordinary Lives pays relatively little attention to the engagement with everyday life in modern literature and visual art. It might seem unfair to criticise such a wide-ranging text for 
what it does not mention, but this is a missed opportunity, and a surprising one given Highmore's claim that he will 'use literature, film and TV, alongside philosophy and critical theory'. (xiii) Art offers a distinctive way of exploring some of the issues in which Highmore is most interested. Literature perhaps has a particular value; as Hoggart argued, it is concerned with the 'experiential wholeness of life-the life of the emotions, the life of the mind, the individual life and the social life, the objectladen world' and explores 'these things all together and interpenetrating', in a 'medium, language' which is not its exclusive possession, but is 'used by everybody in all sorts of everyday situations'. ${ }^{5}$ Highmore's description of the 'literary' qualities of his own style implicitly recognises the importance of this method of negotiating between the general and particular, emotions and the 'object-laden world', and suggests that it would be worth extending his consideration of literature beyond a brief reference to Virginia Woolf's 'Solid Objects', whatever his concerns about a focus on 'finely wrought' ( $\mathrm{x}$ ) artistic works. Art need not displace the everyday, but can explore its texture in particular ways, for which philosophy, sociology and cultural theory cannot substitute.

None of this should distract attention from the value of Highmore's close, sensitive readings of texts, acts and objects. Though he writes in his conclusion that his 'examples have often been microscopic in scale and may seem irreducibly particular in detail', (164) the range of the text successfully demonstrates the richness of ordinary lives. His concern with the density of the everyday is emphasised by his insistence that the phenomena he analyses, ' $[\mathrm{t}]$ he Habitat chair; the "housewife" timing the chores she performs; the teenager being enamoured by the music of the Jam; the drunk white guy demanding the hottest curry in the restaurant ... are not flag bearers, representing a world of chair sitters, music listeners, female and feminist domesticity, and neo-colonial eating', but are 'all they can be: instances of ordinary life intricately entangled with more ordinary life'. (194) They are significant in their own right, not just because they can be used to illustrate some general point, and any analysis must do justice to their particular qualities. This approach recalls one of the original impetuses of cultural studies, the refusal to see ordinary lives, and by extension ordinary people, as an undifferentiated mass. 
Highmore emphasises complexity through his refusal to draw simple, final conclusions and the use of a wide range of analytical models, which suggest that proliferating significance of the acts and objects he considers. His method is perhaps best illustrated by the sixth chapter, which considers the 'cultural density' of 'ordinary occasions of "going for an Indian"', and particularly the consumption of extremely hot curries, an act, Highmore argues, 'that mixes xenophobia and openness'. (162) The chapter emerges from the personal experience of having 'learnt to love' fresh coriander, a process in which, he argues, the herb itself acted as 'a pedagogic guide that trained my taste buds' within the context of 'a much larger cultural and sensual shift that could be called (somewhat blithely, I have to admit) multiculturalism'. (141) He argues for a series of exchanges enacted through 'nonideational signs', such as food, in which even 'excessive chilli eating' can perform valuable 'cultural work'. (162) Multiculturalism is not 'not simply of hearts and minds, but of guts too', (147) and the 'alimentary journey' (162) of the chillies teaches a 'corporeal lesson', (146) enabling a 'discussion' (147) between different cultural traditions despite the 'neo-colonial formations' (148) that frame the consumption of Indian food in Britain. The chapter ranges widely across texts and disciplines to support this argument, considering, amongst other things, Fat Les' 'football anthem' (143) 'Vindaloo', the famous Good Gracious Me comedy sketch in which a group of Indians, 'tanked up on lassis ... go out for an English', (146) Winnicott's theory that eating is a process through which a child gains 'confidence in its physical commerce with the world', (151) ideas of culinary 'authenticity' and 'hybridity', and the history of 'the high street Indian restaurant in Britain'. (155) The result might easily be chaos, particularly as the chapter concludes with a series of explicitly unresolved questions, rather than a final statement about what its material means. In fact, the analysis is nuanced and thought provoking, demonstrating the 'density' (162) of the familiar scene on which it centres and raising the possibility that 'food aggression' (147) might, paradoxically, form part of a 'cultural politics of multiculturalism' (163) thanks to the pedagogic function of the food itself.

Although there are, perhaps inevitably, moments in Ordinary Lives when Highmore slips into a familiar academic style, his writing is, on the whole, clear, engaging, and well-paced. Often it is better than this; he can be evocative and amusing, as he demonstrates when he describes early Habitat customers, with their 
'second-hand pine kitchen tables' and 'jars of Provençal herbs,' as 'the shock troops of gentrification'. (64) His prose is sufficiently flexible for him to complicate and qualify his arguments without being indecisive or vacuous. This flexibility depends upon the use of 'literary' techniques, and, in particular, the development of a distinct authorial voice. As Highmore observes, writing about the everyday means 'getting in among things'. (xiii) Ordinary lives are those we lead ourselves, not distant objects to be held up 'for academic appraisal', (xiii) and personal experience is a critical resource that can help us to trace the lived complexity and fluidity of the everyday, its rhythms and shifts in intensity. Writing about ordinary lives from 'in among' them is difficult, though, and demands an attention to form, as early proponents of cultural studies recognised. Raymond Williams suggested a renewed engagement with 'the realistic novel' as a way of mediating 'fact and feeling'. ${ }^{6}$ There are other possibilities, of course, but academic forms that foster the illusion of a detachment from the messiness of the everyday will not suffice. Highmore could hardly have resolved this problem, but he is conscious of it, and this has helped him to produce a thoughtful, engaging, useful book.

Ben Clarke is an assistant professor of English at the University of North Carolina at Greensboro. He has published on subjects including George Orwell, Virginia Woolf, Englishness, and the politics of style. His first monograph, Orwell in Context, was published in 2007, and he is co-author of Understanding Richard Hoggart (2011).

\footnotetext{
-NOTES

1 Raymond Williams, 'Culture is Ordinary' in Robin Gable (ed.), Resources of Hope: Culture, Democracy, Socialism, Verso, London and New York, 1989, p. 4.

2 Grant Farred, 'Leavisite Cool: The Organic Links Between Cultural Studies and Scrutiny', dispositio/n: American Journal of Cultural Histories and Theories, vol. 21, no. 48, p. 10.

3 Richard Hoggart, Contemporary Cultural Studies: An Approach to the Study of Literature and Society, University of Birmingham, Centre for Contemporary Cultural Studies, Birmingham, 1969, p. 14.

4 Richard Hoggart, 'Literature and Society' in Speaking to Each Other: Volume Two: About Literature, Oxford University Press, New York, 1970, p. 20.

5 Richard Hoggart, 'Why I Value Literature' in Speaking to Each Other: Volume Two: About Literature, Oxford University Press, New York, 1970, p. 13.

${ }^{6}$ Raymond Williams, 'Fiction and the Writing Public', Essays in Criticism, vol. 7, no. 4, p. 48.
} 